\title{
Spinal Cord Injury Units
}

\author{
Hans Frankel, M.B., F.R.C.P., Consultant Physician, National Spinal \\ Injuries Centre, Stoke Mandeville Hospital, Aylesbury, England
}

Many important and exciting developments are reported in this special Silver Jubilee number. With particular concentration on prevention and first aid, it is likely that the number of patients with severe spinal cord lesions will diminish somewhat. It is, however, apparent that a substantial number of patients will be left with severe, permanent neurological lesions which demand early and life long specialised management. For this reason I believe that spinal cord injury units will continue to be required for the forseeable future.

\section{Spinal units in medically sophisticated countries}

The reasons that spinal units exist today are because of poor results obtained when patients were treated sporadically in small numbers in non-specialised departments. Following the onset of a spinal cord lesion, there are multiple physiological problems which inevitably lead to severe complications unless they are anticipated and avoided by an experienced team led by a physician or surgeon with training in and understanding of the problems. Unless there is a full recovery from the spinal cord lesion, the abnormal physiology is life long. It follows that the same specialised and dedicated therapeutic team should supervise the patient's rehabilitation and be available for further help for the rest of the patient's life (Bedbrook, 1985).

It follows from this that the spinal unit team is best able to assess the results of early treatment and should be responsible for that treatment or at least involved in decision making from the first hours after injury. Spinal cord injury units should, therefore:

1. Be capable of admitting a patient within hours of his injury and to undertake his physical, psychological and social rehabilitation.

2. Should be capable of giving a service for life long care.

3. Be capable of undertaking research and ideally have facilities for sport.

\section{Situation of spinal units}

To be able to carry out the functions mentioned above a spinal unit should be situated in or adjacent to:

1. An acute general hospital.

2. An accident hospital.

3. A neurosurgical or orthopaedic department. 
There are now some excellent 'free standing' spinal units and there are also spinal rehabilitation units associated with acute units where the patients spend days or weeks in the acute unit and are subsequently transferred to the spinal rehabilitation unit. The advantages and disadvantages of this last type of organisation were fully aired at the 1967 Annual Scientific Meeting of the International Medical Society of Paraplegia where one of the main subjects was the organisation of spinal units (Paraplegia 1967).

\section{Size of spinal units}

Units may be local, regional or national. A local unit serving a population of less than 2 million is likely to have good community contacts but is likely to be too small to develop the required skills and experience, in certain geographical situations this remains the most logical development.

A regional unit serving populations of approximately 2 million to 10 million, is probably the ideal unit having 40 to 60 beds, with two specialists in spinal cord injuries and adequate supporting staff.

National units serving populations of over 10 million and with over 100 beds, have certain advantages, in particular for research and teaching. Such units may, however, have organisational problems and it is likely that many of the patients will live far from the parent unit.

\section{Spinal units in developing countries}

The treatment of spinal cord injuries is labour intensive and in countries where semi-skilled labour and family help are easily found, there are opportunities to develop an effective service. The absence of sophisticated diagnostic and therapeutic facilities is not a great disadvantage as long as basic aids such as simple wheelchairs are available. In order for such 'basic' spinal units to succeed, it is essential for the doctor in charge to have adequate training and experience and it is becoming one of the most important functions of the International Medical Society of Paraplegia to assist in such training.

\section{Design and staffing of spinal units}

All spinal units must have adequate wheelchair access to all the facilities. There are great advantages in nursing patients in large, open wards and there are considerable disadvantages in nursing patients entirely in single rooms. In most spinal units today there is a compromise between these two systems.

The skill, experience and dedication of the staff is of much greater importance than the physical facilities. Doctors, nurses and therapists as well as social workers, must work together as an effective team. One of the great advantages of an established spinal unit is the major contribution that the patient community makes to the overall rehabilitation of the new patients.

\section{References}

BEDBROOK G (ed) (1985) Lifetime care of the paraplegic patient. Churchill Livingstone, Edinburgh

Proceedings of the 1967 Annual Scientific Meeting of the International Medical Society of Paraplegia: Organisation of Spinal Units. Paraplegia 5:115-187 